International Journal of Engineering \& Technology, $7(4.19)(2018) 994-1000$
International Journal of Engineering \& Technology
SPC
Website: $w$ ww.sciencepubco.com/index.php/IJET
Research paper

\title{
Numerical and Experimental Study the Effect of Solid Particles Flow on Heat Pipe Performance
}

\author{
Hafidh Hassan Al-Ghazali ${ }^{*}$, Mohammed Wahhab Aljibory ${ }^{2}$, Taher Habeeb Alkharasani ${ }^{3}$ \\ ${ }^{I}$ Mech. Eng. Dep, University of kufa, alnajaf \\ ${ }^{2}$ Mech. Eng. Dep, University of Kerbala, Kerbala \\ ${ }^{3}$ Mech.Eng. Dep, University of Kerbala, Kerbala \\ *Corresponding Author E-mail: hafidh.alghazali@uokufa.edu.iq
}

\begin{abstract}
A numerical work supported by experimental results was carried out to studying of passing a hot solid particle on heat pipe performance. used Ansys fluent 18.0 as a computer program, geometry was published using design modular engaged in it. 3Dimention model with the steady state was studied to knowing the temperature distributed inside the evaporator and condenser part domain, more clearly to particle behavior and streamline 2Dimention model with transient was studied also. Depended on particle of $105 \mu \mathrm{m}$ diameter and experimental measuring properties set with height range $(2.5$ to 5$) \mathrm{cm}$ inside evaporator part from box, velocity with range $(0.8739$ to 1.377$) \mathrm{m} / \mathrm{s}$ was take in consideration, the result shown enhancement in Nusselt number by (58) \% when the velocity $1.377 \mathrm{~m} / \mathrm{s}$ and particle bed height $5 \mathrm{~cm}$ compared with the first state, pressure drop with acceptable range was measured not exceed (42) \%
\end{abstract}

Keywords: heat pipe, fluidization, particle bed

\section{Introduction}

Heat pipes is a kind of heat exchanger its consist of hollow pipe always from copper or steel and closed from two ends there was a liquid butting inside as working fluid some time there is a wick inside heat pipe or without wick at this case its name thermosiphons, working fluid in charge of transfer heat from evaporator to condenser part by evaporating working fluid in evaporator and condensing in condenser part. Afterward the heat pipe creation greatly development happened through the last time according to the project building and working fluid etc. Faghri [1]studied the developments heat pipe knowledge with various heat pipes kinds , heat pipe study, and imitations. There were many applications for Heat pipes like electronic freshening [2],renewable Energy used as heat recovery[3]heat exchangers [4], Current advances in coolant liquid like Nanofluid which product more development in heat pipe knowledge in the application of cooling electronic parts. [5] studied the stream and heat transfer features for Nanofluids below free and forced convection styles. This research shown the Nanofluids expressively enhanced a heat transfer ability of conventional fluids like oil -water mixture. Also stated that the purpose for improvement is due to the developed thermal conductivity of the postponed nanoparticles mixing the main fluids. Following many practical studies, Z.-H. Liu,[6] several kinds of Nanofluids (silver copper- Al2O3- diamond and gold), used inside heat pipes heat transfer was an enhancement for all cases with a different amount.
The investigator showed that the improvement in heat transfer isn't because enhancement in thermos physical properties for Nanofluids, also because of the nature of the surface shaped through the hot procedure in the evaporator part. Likewise, many numerical types of research have been achieved to forecast the heat transfer development of Nanofluid by conservative mathematical methods, (LBM) Technique [7]. Though the enhancement in heat transfer in numerical method still not understood completely since that enhancement take place at the micro structure level, later additional numerical revisions are needed lot of understandings the improvement mechanism. Tien and Rohani [8] examined the affects variation of vapor pressure according to vapor temperature supply, condensation and evaporation mode, also general heat pipe performance. Chen and Faghri [9] examined a heat conduction among the wall and liquid-wick border and the compressibility properties. Huckaby et al. [10] made a one-dimensional study using a collocation-spectral technique to compute the dynamic performance of vapor flow inside the heat pipe, Two-dimensional, heat pipe at a transient study model was established.

Legierski et al. [11] shown a study on the measurements and modeling of mass and heat transfer in heat pipes by means of the FLUENT profitable code. Xiao and Faghri [12] advanced a threedimensional typical to study the thermal hydrodynamic performances of flat heat pipes deprived of empirical correlations Shafahi et al.[13] advanced an analytical model to study the thermal presentation of quadrilateral also heat pipe with disk-shaped with Nano-fluids as a working fluid, velocity and pressure variation of 
liquid, distribution of temperature, for the wall of the heat pipe, temperature inclines lengthways the heat pipe is got. Thermal confrontation at various heat loading was got for heat pipe with flatshaped. Do et al. [14] research the effect Al2O3 as Nanofluid for water-based on heat transfer act of a plane micro-heat pipe with a quadrilateral fluted wick. 1D conduction calculation for the partition and Young-Laplace equation to phase alteration procedure was resolved to forecast the axial differences of the temperature for the wall at evaporation also at condensation degrees. The thermos physical advantage of Nanofluids, the surface physiognomies shaped by nanoparticles like tinny porous covering also measured in that mode.

One most important method to developed heat pipe performance was used it in high heat transfer coefficient domain, and that could be done by fluidization which is butting small particle in the domain and move it by an external force such as air or liquid this two-phase create sever increasing in domain heat transfer coefficient

Vreedenburg, H.A [15] studied the heat transfer coefficient between the horizontal stainless stile pipe and fluidize inside cylinder with diameter of $0.565 \mathrm{~m}$ The tube was lay at $0.85 \mathrm{~m}$ overhead the orifice type supplier plate the static head height was $1.2 \mathrm{~m}$ the researcher studied pipe diameter, bed density, air velocity and particle shape on heat transfer coefficient and found at increased velocity and decreasing heat pipe diameter the heat transfer coefficient was increased also effect of particle bed diameter was studied

Ainshtein [16]studied the effect of distributed blat distance effect on the horizontal tube at fluidization the result shown that heat transfer coefficient was increased with decreased distinctly between blat and pipe also shown that particle diameter was a most parametric effect on it. Salwe [17] Study experimentally heat transfer coefficient between heated tube immersed in bubbling (gas-solid) fluidize at different air superficial velocities, and particle diameters. The bed was silica sand particles with diameter $(200,350$ and 500) $\mu \mathrm{m}$, the result showed increased heat transfer coefficient with increased air superficial velocity, and decreased by increased particle diameter. S. Lechner et al[18] examines the heat transfer by fluidized beds when used a cylindrical heater, for just one and also when used many of them, also study changing fluidize bed material effect on heat transfer. The bed area was $0.15 \mathrm{~m} 2$, used (lignite) as a solid particle. the result showed that the tube array decreases the heat transfer coefficient because of particle -gas flow turbulences produced via the occupied tubes, the study found a less particle diameter product more heat transfer. Hafidh .H [19]

performed experimentally circulation fluidize bed to explain fluidization effect on heat transfer coefficient, the experimental rig was fabricated from tube with $1500 \mathrm{~mm}$ long and inner diameter $76 \mathrm{~mm}$, used cylindrical heater with $28 \mathrm{~mm}$ diameter, the power supply was changed $(50,105$ and190) W. air velocity supply at $(4.97,5.56,6) \mathrm{m} / \mathrm{s}$, different particle size used (194-356) $\mu \mathrm{m}$, with particle bed thickness $(15-35) \mathrm{cm}$

The result shown that heat transfer coefficient and heat flux increased with increasing velocity and particle thickness which represent density but that dependence inversely with particle size. Q.F. Hou [20]Study The effect of fluidize material properties, gas velocity and tube array on heat transfer between fluidize bed and tubes are examined, by the two method of computational fluid dynamics, discrete element way, the result shown that if the material have a small cohesive the conductive heat transfer between a fluidized bed and a tube is dominant and the convective heat transfer is dominant for big non-cohesive particles, the gas velocity have sever effect on particle uniformity and heat distributed ,the tubes was arrange as line and staggered type to shown that's two sort effect on microscopic properties such as porosity and number of contact the surface, due to that comprehend led to choses suitable tubes sort

\section{Experimental setup}

Experimental part includes from three heat pipes, wooden box, data acquisition, electrical heater, cyclone and air blower. The three heat pipe were fabricated from copper pipe with outer diameter 22.225 $\mathrm{mm}$ and with inner diameter $19.8 \mathrm{~mm}$ turn inside each on stainless steel wick with 180 pore per inch and with wire diameter of 0.11 $\mathrm{mm}$, evacuated each pipe and leave it for two days to ensure no leak inside ,after calculate amount of working fluid that saturated that heat pipe found equal $65.56 \mathrm{ml}$.each heat pipe butting horizontally in wooden box divided to two part to create evaporator and condenser part with length $(64.5$ and 34.5$) \mathrm{cm}$ respectively and with adiabatic part with $1 \mathrm{~cm}$, the front side fabricated from classes to be easy to espies what happened inside, each part from box air interring inside, at constant rate in condenser and with different rate at evaporator part $(0.133,0.171$ and 0.209$) \mathrm{kg} / \mathrm{s}$, inside evaporator part particle with diameter $106 \mu \mathrm{m}$ was putting inside with different height $(2.5-5) \mathrm{cm}$, there were cloth inside evaporator part to prevent particle to back to airline ,the air passed over electrical heater and pass over particle that makes particle moved up and hit the pipe put part of particle exit from the top cyclone was effect way to return it to box .air flow rate measured by velocity meter with uncertainty \pm $0.2 \%$, and there were 28 thermocouples with $\mathrm{k}$ type with an accuracy $\pm 0.1{ }^{\circ} \mathrm{C}$ are distributed 5 over each pipe in evaporator part and 1 in condenser part and one after and another before each pipe in evaporator and condenser and at inlet and exit of each part all that thermocouples connected to data logger and during experimental the study stat degree was record in data logger which run with time interval 2 minutes the experimental procedure done by calculate heat gain in evaporator part in each pipe and changing flow rate inside $(0.133,0.171$ and 0.209$) \mathrm{kg} / \mathrm{s}$ that take superficial velocity $(0.8739,1.1236$ and 1.377$) \mathrm{m} / \mathrm{s}$ respectively , also changing particle bed height $(0,2.5,5,7.5$ and 10$) \mathrm{cm}$ for at each flow rate figure (1) shown rig schematic diagram, figure (2) rig photo .

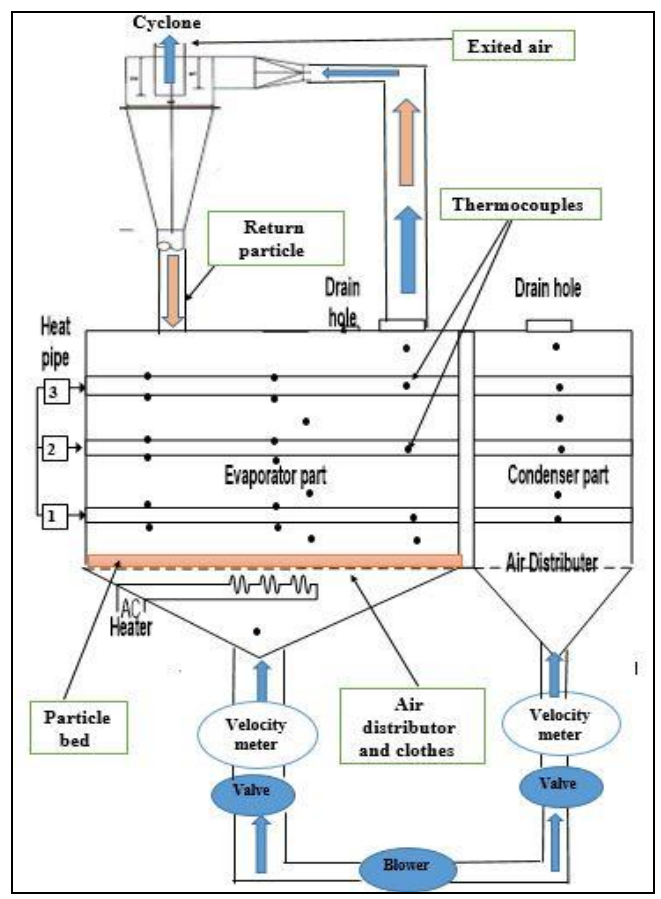

Fig. 1: rig schematic diagram 


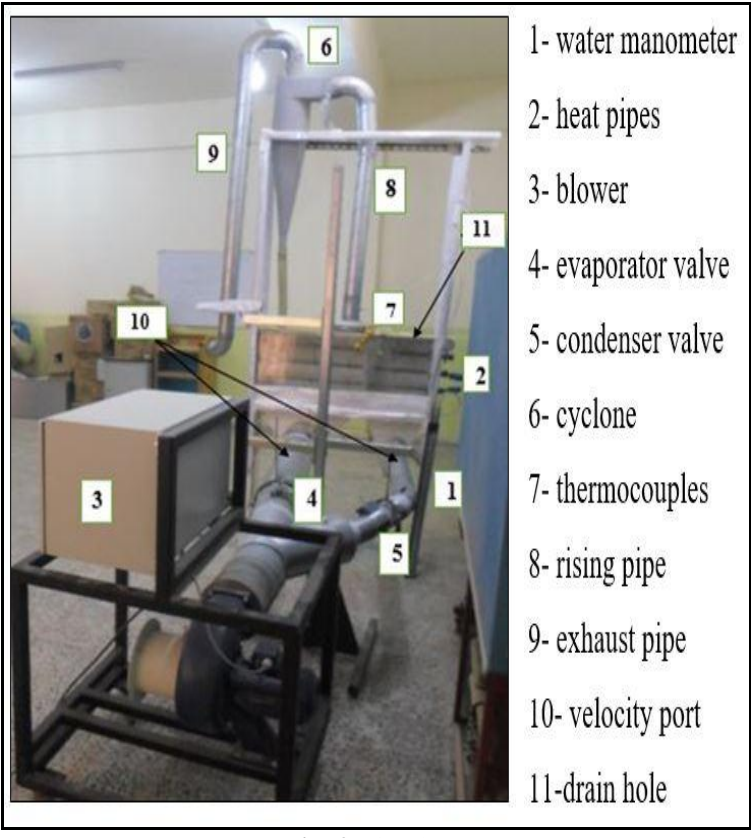

Fig. 2: rig photo

\subsection{Errors analysis}

To calculate error analysis, repeated the reading for all thermocouples for four times, take water boiling point as a reference. Standard and the main standard deviation was calculated as follows:

$$
\sigma=\sqrt{\frac{\sum_{1}^{n}\left(x_{i}-\bar{x}\right)^{2}}{n-1}} \quad, \quad \sigma_{m}=\frac{\sigma}{\sqrt{n}}
$$

Where $\sigma$ is the standard deviation

$\sigma_{m}$ is the mean standard deviation

$X_{i}$ is the values of temperature reading

$\overline{\mathcal{X}}$ is the mean of values temperature reading

$\mathrm{n}$ is the number of reading of temperature.

As the true value (x) was also calculated by

$$
x=\bar{x} \pm \sigma_{m}
$$

\begin{tabular}{|c|c|c|}
\hline THER.NO & percentag & ertintity 56 \\
\hline THER. 1 & 0.773985318 & -0.786154763 \\
\hline THER. 2 & 0.982676464 & -1.002376704 \\
\hline THER. 3 & 0.990788045 & -1.010818176 \\
\hline THER. 4 & 1.02214531 & -1.043477012 \\
\hline THER.5 & 1.159403762 & -1.186926298 \\
\hline THER. 6 & 1.131340125 & -1.157531358 \\
\hline THER. 7 & 0.982676464 & -1.002376704 \\
\hline THER. 8 & 0.773985318 & -0.786154763 \\
\hline THER. 9 & 1.131340125 & -1.157531358 \\
\hline THER. 10 & 0.990788045 & -1.010818176 \\
\hline THER.11 & 1.02214531 & -1.043477012 \\
\hline THER.12 & 1.04194514 & -1.064120238 \\
\hline THER.13 & 1.351235735 & -1.38876676 \\
\hline THER.14 & 0.881736012 & -0.897564307 \\
\hline THER.15 & 1.164920672 & -1.192708897 \\
\hline THER.16 & 0.995459858 & -1.015681256 \\
\hline THER. 17 & 0.881736012 & -0.897564307 \\
\hline THER.18 & 1.351235735 & -1.38876676 \\
\hline THER.19 & 0.995459858 & -1.015681256 \\
\hline THER. 20 & 1.351235735 & -1.38876676 \\
\hline THER. 21 & 0.773985318 & -0.786154763 \\
\hline THER. 22 & 0.990788045 & -1.010818176 \\
\hline THER. 23 & 0.990788045 & -1.010818176 \\
\hline THER. 24 & 1.159403762 & -1.186926298 \\
\hline THER.25 & 1.131340125 & -1.157531358 \\
\hline THER. 26 & 0.982676464 & -1.002376704 \\
\hline THER. 27 & 1.164920672 & -1.192708897 \\
\hline TUCO no & 1.351235735 & -1.38876676 \\
\hline
\end{tabular}

Figure (3) represent thermocouples errors value

Fig. 3: thermocouples errors value

\section{Numerical analysis}

\subsection{Model description}

In present work sketch 3D model to represent hat temperature distributed and also 2D model to explain velocity vector and particle distribution since it gives clear vision, used design modular engaged in Ansys fluent 18.0, firstly sketch rectangular shape at Z-X plane with length $100 \mathrm{~cm}$ and width $19.5 \mathrm{~cm}$ and sketch line at $64.5 \mathrm{~cm}$ from length start, generate and extrude at $\mathrm{Y}$ axis, at $\mathrm{Y}-\mathrm{Z}$ plane sketch three circles with diameter $2.22225 \mathrm{~cm}$ and generate and extrude it at X-axis. Transfer Z-X axis from bottom to object top and sketch two circles at each part represent exit ports at each evaporator and condenser part as a cut material with $10.16 \mathrm{~cm}$ diameter. Figure (4) represent body geometry

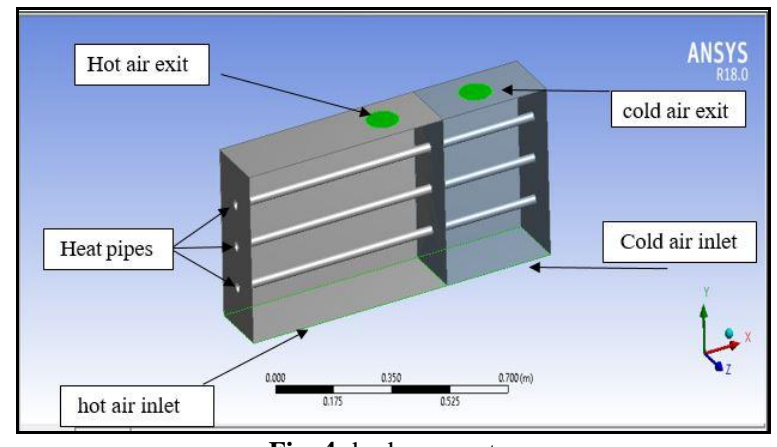

Fig. 4: body geometry

\subsection{Assumption made}

Before start write governing equation following assumption was made.

Study state for 3D model and transient for 2D model.

Turbulent flow

Temperature base solver

In $\mathrm{Y}$ direction gravity was $-9.81 \mathrm{~m} / \mathrm{s}^{2}$

\subsection{Boundary conditions}

At the wall roughness friction was 0.5 taken from previous studied and suppose all wall was isolated and Amount of air interring to evaporator part after heated it very important parameter, that air inter with amount ( 0.133 to 0.209$) \mathrm{kg} / \mathrm{s}$ and superficial velocity depend on air amount from $(0.8739$ to 1.377$) \mathrm{m} / \mathrm{s}$ the inlet surface set as (wall jet) to prevent particle backflow to airline, at exit port set as (reflect surface ) to prevent particle run out of box, at exit pressure was set as atmospheric pressure $(\mathrm{Po}=0)$, to simplify case take evaporator and condenser part separately and since geometry was symmetric take half width at three dimension also to more simplify take heat pipe surface temperature as boundary condition and take it from experimental to prevent meshing inside pipe ,heat pipe surface set as (tape) option because some particle residual on heat pipe surface, at condenser part set air flow $(0.0285) \mathrm{kg} / \mathrm{s}$ and outlet atmosphere pressure and also heat pipe surface temperature getting from experimental figure (5) below listed the boundary conditions . 


\begin{tabular}{|c|c|c|c|c|}
\hline & \multicolumn{3}{|c|}{ EVAPORATOR PART } & \\
\hline & HEAT PIPE SURFACE & INLET & OUTLET & WALL \\
\hline 1 & (tabe) & $\mathrm{V}=0.133-0.209 \mathrm{~m} / \mathrm{s}$ & reflect surface & \\
\hline \multirow[t]{2}{*}{2} & \multirow{2}{*}{$\begin{array}{c}\text { surface temp. from } \\
\text { expermantil }\end{array}$} & \multirow{2}{*}{$\mathrm{m}=0.8739-1.377 \mathrm{~kg} / \mathrm{m} 3$} & \multirow[t]{3}{*}{ Pout $=0.0$} & roughness \\
\hline & & & & frection $=$ \\
\hline \multirow[t]{3}{*}{3} & & (wall jet) & & 0.5 \\
\hline & \multicolumn{3}{|c|}{ CONDENSER PART } & \\
\hline & HEAT PIPE SURFACE & INLET & OUTLET & WALL \\
\hline 1 & & \multirow{2}{*}{$\begin{array}{c}\text { air flow rate }=0.028 \\
\mathrm{~kg} / \mathrm{m} 3\end{array}$} & pout $=0.0$ & \\
\hline \multirow[t]{2}{*}{2} & \multirow{2}{*}{$\begin{array}{c}\text { surface temp. from } \\
\text { expermantil }\end{array}$} & & & roughness \\
\hline & & & & frection = \\
\hline 3 & & & & 0.5 \\
\hline
\end{tabular}

Fig. 5: Boundary conditions

\subsection{Simulation model}

Eulerian-Eulerian model was used because of it suitable to present work (two-phase flow air and cement fly ash), also enabled energy equation.

\subsection{Governing Equation}

The Eulerian model means the program solve with continuity, momentum, conservation as well as energy equation if the flow deal with granular or no

The result was different, CFD used the following general equations.

\subsubsection{Continuity equation}

Continuity equation used at the fluidized bed to calculate volume friction, for mixture volume friction was calculated from the equation

$$
\frac{1}{\rho_{\mathrm{rq}}}\left(\frac{\partial}{\partial \mathrm{t}}\left(\alpha_{\mathrm{q}} \rho_{\mathrm{q}}\right)+\nabla \cdot\left(\alpha_{\mathrm{q}} \rho_{\mathrm{q}} \overrightarrow{\mathrm{v}}_{\mathrm{q}}\right)=\sum_{\mathrm{p}=1}^{\mathrm{n}}\left(\dot{\mathrm{m}}_{\mathrm{pq}}-\dot{\mathrm{m}}_{\mathrm{qp}}\right)\right)
$$

\subsubsection{Momentum equation}

For granular solid-liquid flow, momentum equation could be written as

$$
\begin{aligned}
\frac{\partial}{\partial \mathrm{t}}\left(\alpha_{\mathrm{s}} \rho_{s} \overrightarrow{\mathrm{v}}_{\mathrm{s}}\right)+\nabla \cdot\left(\alpha_{\mathrm{s}} \rho_{\mathrm{s}} \overrightarrow{\mathrm{v}}_{\mathrm{s}} \overrightarrow{\mathrm{v}}_{\mathrm{s}}\right)= & -\alpha_{\mathrm{s}} \nabla \mathrm{p}-\nabla \mathrm{p}_{\mathrm{s}}+\nabla \cdot \tau_{\mathrm{s}}+\alpha_{\mathrm{s}} \rho_{\mathrm{s}} \overrightarrow{\mathrm{g}} \\
& +\sum_{\mathrm{l}=1}^{\mathrm{N}}\left(\mathrm{K}_{\mathrm{ls}}\left(\overrightarrow{\mathrm{v}}_{\mathrm{l}}-\overrightarrow{\mathrm{v}}_{\mathrm{s}}\right)+\dot{\mathrm{m}}_{\mathrm{ls}} \overrightarrow{\mathrm{v}}_{\mathrm{ls}}-\dot{\mathrm{m}}_{\mathrm{sl}} \overrightarrow{\mathrm{v}}_{\mathrm{sl}}\right) \\
& +\left(\overrightarrow{\mathrm{F}}_{\mathrm{s}}+\overrightarrow{\mathrm{F}}_{\mathrm{lift}, \mathrm{s}}+\overrightarrow{\mathrm{F}}_{\mathrm{vm}, \mathrm{s}}\right)
\end{aligned}
$$

\subsubsection{Energy equation}

Energy equation could be written for each phase separately

$$
\begin{aligned}
& \frac{\partial q Q}{\partial t}(\alpha q \times \rho q \times h q)+\nabla \cdot(\alpha q \times \rho q \times h q \times \vec{u})=-\alpha q \frac{\partial p q}{\partial t}+\tau q: \\
& \nabla \vec{u} q-\nabla \cdot \vec{q}+S q+\sum_{p=1}^{n}(Q p q+\dot{m} p q \times h p q-\dot{m} p q \times h p q)
\end{aligned}
$$

\subsubsection{Turbulence Model}

Ansys 18.0 has many turbulent model option put most suitable for fluidized bed was RNG model.

$$
\begin{aligned}
& \frac{\partial}{\partial \mathrm{t}}\left(\rho_{\mathrm{m}} \mathrm{k}\right)+\nabla \cdot\left(\rho_{\mathrm{m}} \overrightarrow{\mathrm{v}}_{\mathrm{m}} \mathrm{k}\right)=\nabla \cdot\left(\frac{\mu_{\mathrm{t}, \mathrm{m}}}{\sigma \mathrm{k}} \nabla \mathrm{k}\right)+\mathrm{G}_{\mathrm{k}, \mathrm{m}}-\rho_{\mathrm{m}} \in \\
& \frac{\partial}{\partial \mathrm{t}}\left(\rho_{\mathrm{m}} \in\right)+\nabla \cdot\left(\rho_{\mathrm{m}} \overrightarrow{\mathrm{v}}_{\mathrm{m}} \in\right)=\nabla \cdot\left(\frac{\mu_{\mathrm{t}, \mathrm{m}}}{\sigma_{\epsilon}} \nabla \epsilon\right)+\frac{\epsilon}{\mathrm{k}}\left(\mathrm{C}_{1 \epsilon} \mathrm{G}_{\mathrm{k}, \mathrm{m}}-\mathrm{C}_{2 \epsilon} \rho_{\mathrm{m}} \in\right)
\end{aligned}
$$

The constant values used in turbulent equation listed below in figure (6)

\begin{tabular}{|l|l|}
\hline The constant & Value \\
\hline $\mathrm{C}_{\mathrm{mu}}$ & 0.0845 \\
\hline $\mathrm{C}_{1}-$ Epsilon & 1.42 \\
\hline $\mathrm{C}_{2}-$ Epsilon & 1.68 \\
\hline Dispersion Prandtl number & 0.75 \\
\hline
\end{tabular}

Fig. 6: constant for turbulent equation

\subsection{Meshing}

Choosing mesh kind very important to time reach convergent, there were many meshing methods should be choosing the correct one depending on geometry and flow. in the two-dimension model used small element (hexahedral) engaged in Ansys 18.0 with (4.5702*10$5),(4.5702 * 10-3)$ maximum and minimum respectively. a number of node and element was (74608), (73705) respectively. in threedimension model used small element (tetrahedral) engaged in Ansys 18.0 with $\left(7.7997 * 10^{-5}\right),\left(7.7997 * 10^{-3}\right)$ maximum and minimum respectively. a number of node and element was (265908), (1464078) respectively. Figure (7), (8) represent 2D,3D mesh.

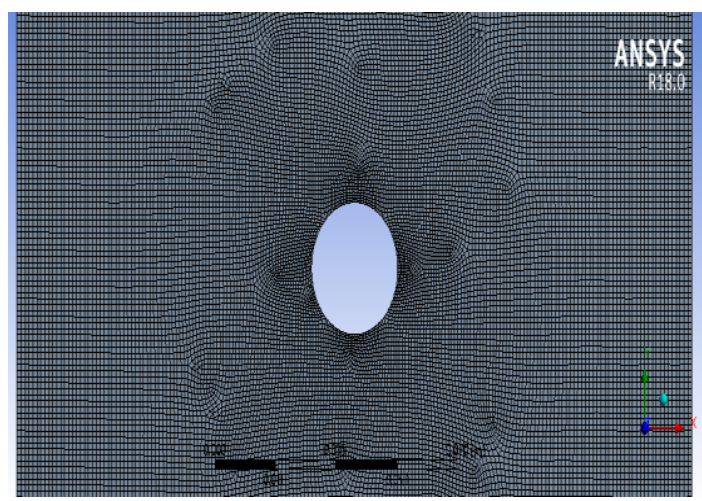

Fig. 7: 2 Dimension mesh

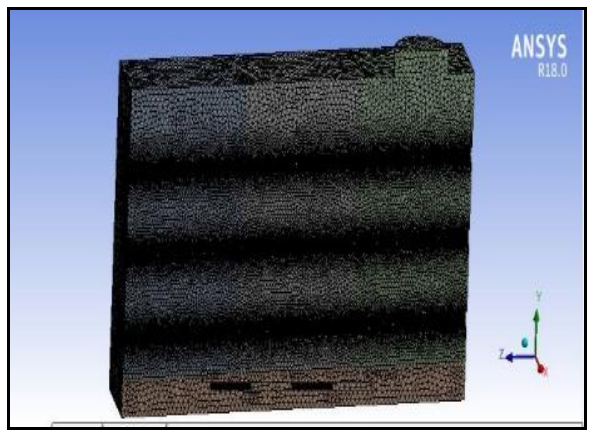

Fig. 8: 3 Dimension mesh 


\section{Results and discussions}

\subsection{Pipe location effect}

Figure (9) shown that heat pipe number (1) have the biggest amount of heat gain as compared with heat pipe number (3) reach to $57 \%$ that because it's closed to the heat source and more particle amount impact pipe surface

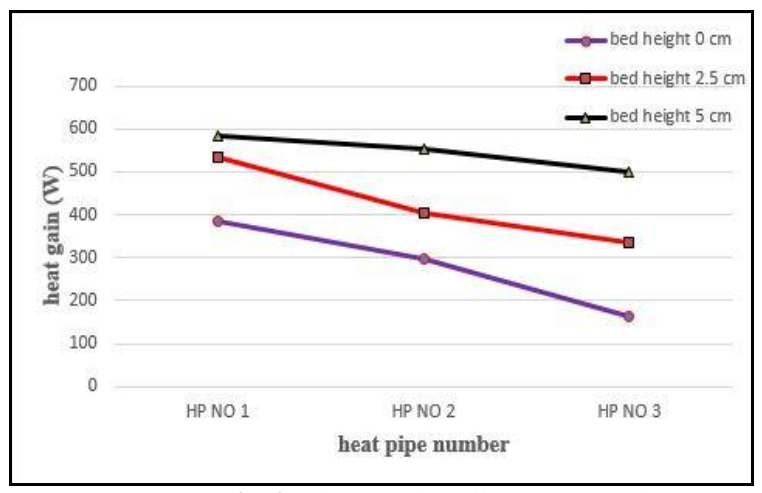

Fig. 9: pipe location effect on heat gain

\subsection{Particle bed height effect}

Figure (10) represent particle bed effect on heat pipe evaporator gain, clearly shown increased heat gain due to increased particle bed height for all heat pipes. because of more particle hit heat pipe surface and that means more heat loader hitting pipe surface, increased bed from ( 0 to 5 ) $\mathrm{cm}$ increased heat gain by $68 \%$. figure (11) contour of heat distributed at evaporator part particle bed height $5 \mathrm{~cm}$ and at superficial velocity $1.337 \mathrm{~m} / \mathrm{s}$.

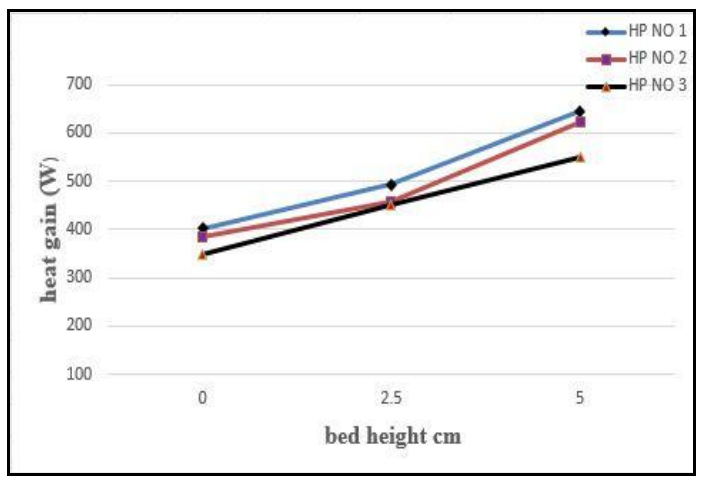

Fig. 10: bed effect at a superficial velocity $1.337 \mathrm{~m} / \mathrm{s}$

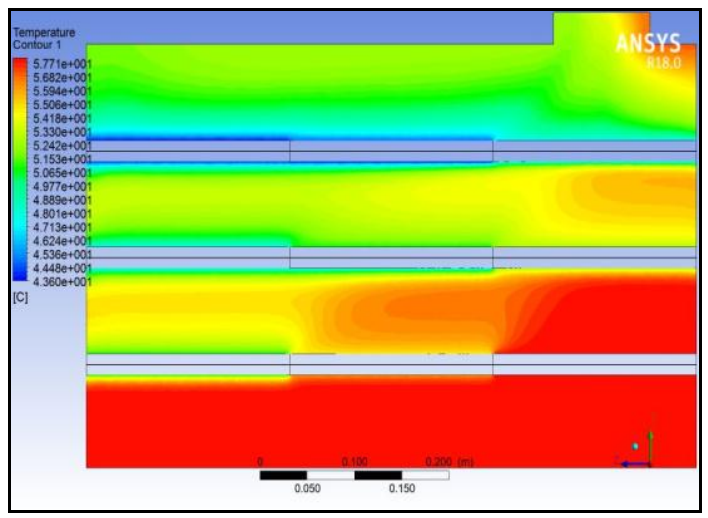

Fig. 11: 3D heat distribution at bed $5 \mathrm{~cm}$ and superficial velocity $1.337 \mathrm{~m} / \mathrm{s}$

\subsection{Velocity effect}

Figure (12) represent simple for velocity effect on heat gain in heat pipe evaporator part, figure shown at increasing velocity increased heat gain because of more particle hit pipe surface for a unit time, increased superficial velocity $(0.8739$ to 1.377$) \mathrm{m} / \mathrm{s}$ increased heat gain by $36 \%$.

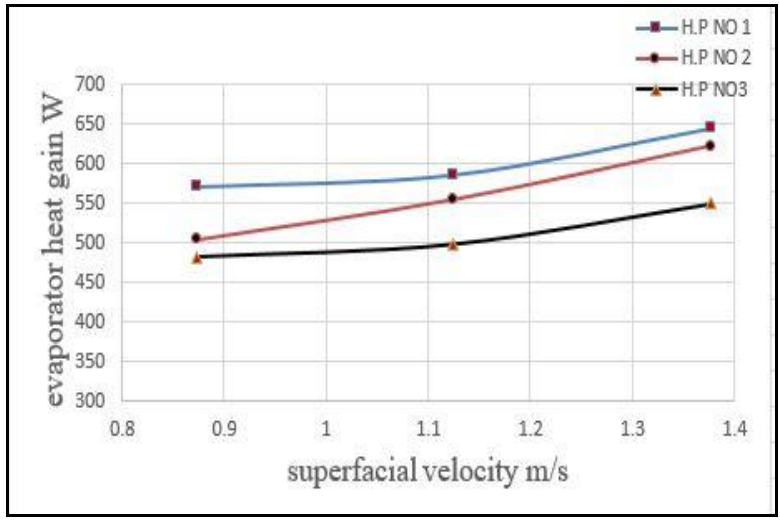

Fig. 12: velocity at particle bed height $5 \mathrm{~cm}$

\subsection{Porosity variation}

Figure (13) represent porosity variation with velocity and particle bed height, the figure shown at increasing particle bed height degreased porosity because of decreased distance between particle at constant volume. also increasing velocity decreased porosity because at high velocity increased pressure drop inside the domain

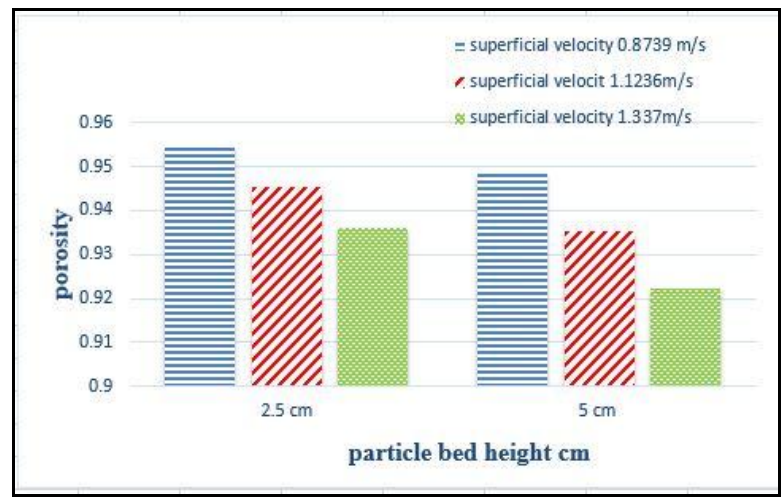

Fig. 13: porosity variation with bed and velocity

\subsection{Pressure drop variation}

Figure (14) shown pressure drop at superficial velocity (0.8739 to $1.377) \mathrm{m} / \mathrm{s}$ and particle bed height (0 to 5) $\mathrm{cm}$, the figure obviously shown increasing particle from (o to 5) $\mathrm{cm}$ increased pressure drop by $43 \%$ due to increased flow resistance also increased velocity from (0.8739 to 1.377 ) increased pressure drop by $33 \%$. 


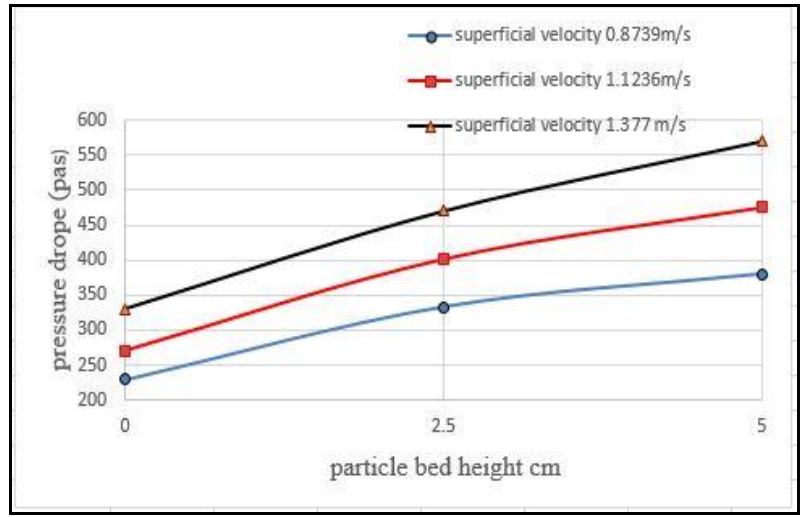

Fig. 14: pressure drop at a different velocity and bed

\subsection{Variation of heat transfer coefficient}

Figure (15) represent the relationship between heat transfer coefficient and particle bed height at a superficial velocity of 1.377 $\mathrm{m} / \mathrm{s}$. could observe clearly increasing heat transfer coefficient due to increased particle bed height. because increased fluidization and that lead to increased convection coefficient for air- particle mixture, studies. The study shown that increasing heat transfer coefficient by $89 \%$ when increased particle bed height from (0 to 5$) \mathrm{cm}$.

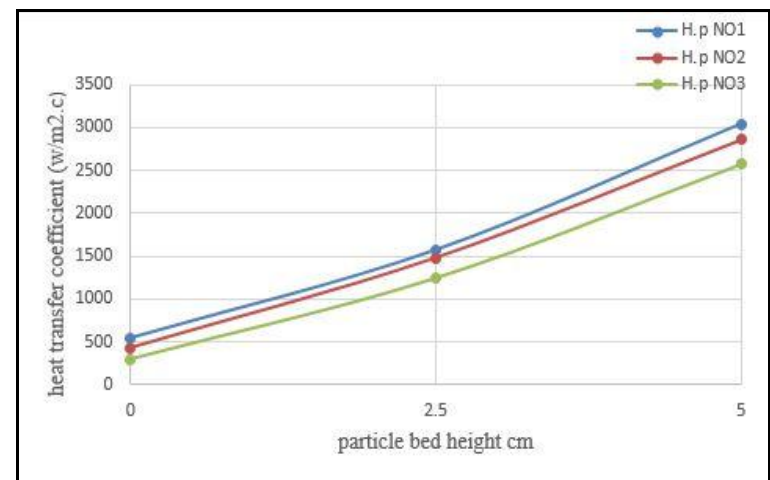

Fig. 15: heat transfer coefficient at different particle bed height and velocity $1.377 \mathrm{~m} / \mathrm{s}$

\subsection{Heat pipe surface temperature}

Figure (16) represents air velocity vector at a particle bed height 5 $\mathrm{cm}$ and air superficial velocity $0.8739 \mathrm{~m} / \mathrm{s}$. the figure showed that the number of particles that hit the lower heat pipe surface was more than the upper one. because separation occurs at the upper heat pipe surface, the deviation between upper and lower heat pipe temperature ( 2 to 4$) \%$

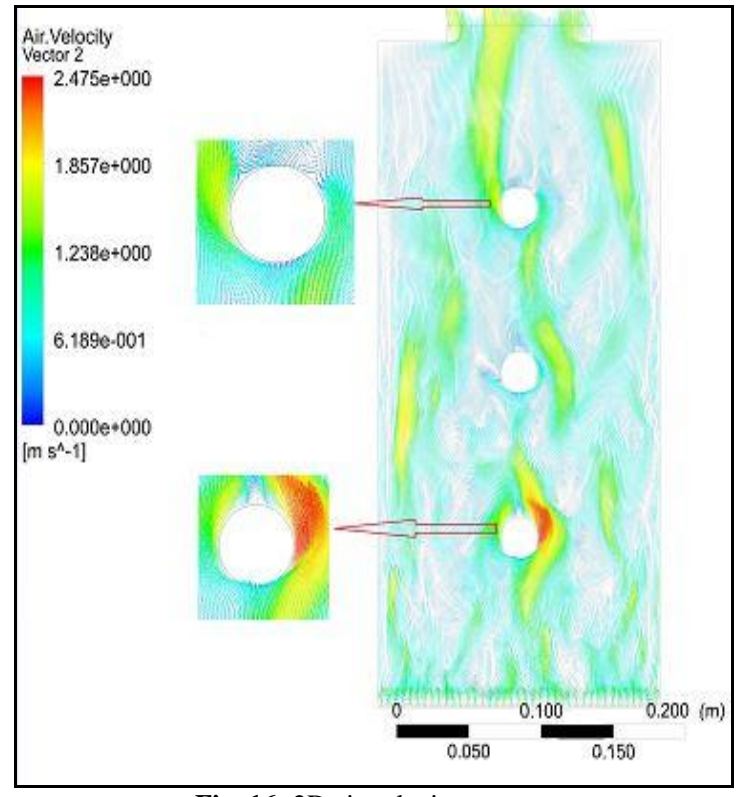

Fig. 16: 2D air velocity contour

\subsection{Condenser part temperature}

Figure (17) shown heat distribution inside the condenser part. It seems that the air enters with a low temperature and hits the heat pipe surface. therefore, the pipe surface temperature decrease while the surrounding area temperature increased, when this process happens to the second upward pipe, the impact will be less. So, the absorbed temperature by the pipe is less than the previous one. When this occurs to the third upward pipe, the absorbed impact will be least where the surrounding are needless to get more temperature from the pipe surface. In sum, the third pipe is the hottest one if compared with the previous downward pipes

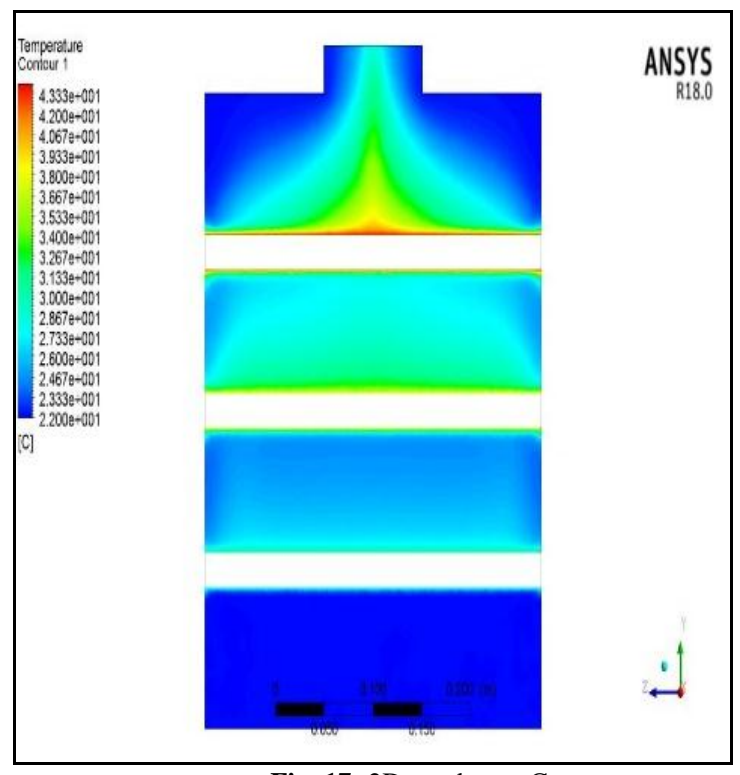

Fig. 17: 2D condenser Contour

\section{9 (Nusselt -Reynolds) number relation}

Figure (18) represent the relationship between Nusselt and Reynolds number, for three heat pipes at a superficial velocity $1.1236 \mathrm{~m} / \mathrm{s}$. 
clearly could note with increased Reynolds number Nusselt number was increased also due to increasing heat transfer coefficient.

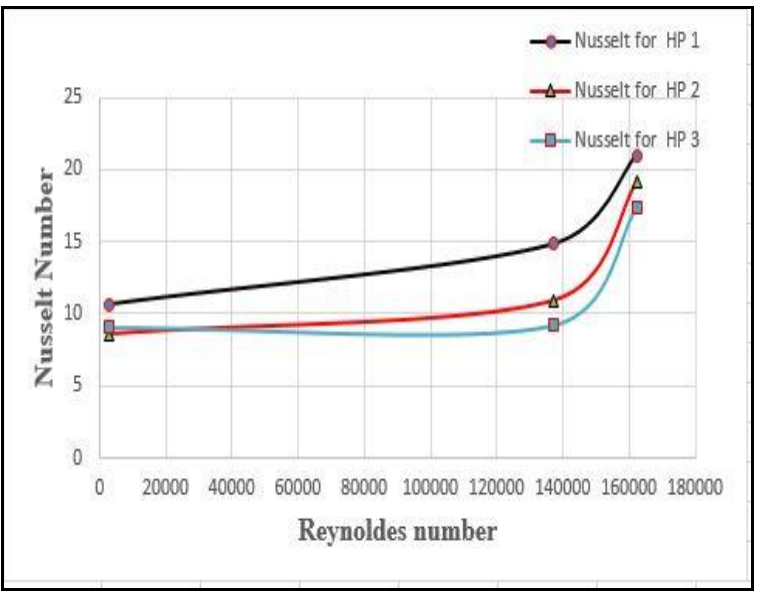

Fig. 18: (Nusselt -Reynolds) relationship

\section{Conclusions}

From numerical and experimental procedure can be obtained the flowing conclusions:

1- heat gained in heat pipe number (1) was greater than heat pipe number (3) which is about (55) \% at a superficial velocity of 1.377 $\mathrm{m} / \mathrm{s}$. and particle bed height $5 \mathrm{~cm}$. maximum heat transfer to condenser part was $31.7 \%$.

2- increasing particle height inside the wooden box by $5 \mathrm{~cm}$. increased heat gained in heat pipe by $37.2 \%$

3 - increasing Reynolds number from 2400 to 206113 increased the heat gained by $72.5 \%$.

4-maximum Nusselt number is (25.2) which obtained at Reynolds number 206113 and at particle bed height $5 \mathrm{~cm}$

\section{References}

[1] Faghri, "Review and advances in heat pipe science and technology, ASME J. Heat Transfer 134 (2012) 123001. 1-18."

[2] M. S. M. Groll, "V. Sartre, M.C. Zaghdoudi, M. Lallemand, Thermal control of electronic equipment by heat pipes, Revue Générale de Thermique 37 (5) (1998) 323-352."

[3] R. H. H.N. Chaudhry, "S.A. Ghani, A review of heat pipe systems for heat recovery and renewable energy applications, Renew. Sustainable Energy Rev. 16 (2012) 2249-2259."

[4] X. Yang, Y.Y. Yan, "Mullen, Recent developments of light weight, high performance heat pipes, Appl. Therm. Eng. 33-34 (2012) 1-14."

[5] P. S. Kakaç, "Review of convective heat transfer enhancement with nanofluids, Int. J. Heat Mass Transfer 52 (2009) 3187-3196."

[6] Y.-Y. L. Z.-H. Liu, "A new frontier of nanofluid research Application of nanofluids in heat pipes, Int. J. Heat Mass Transfer 55 (2012) 6786-6797."

[7] R. S. A. Kamyar, "M. Hasanuzzaman, Application of computational fluid dynamics (CFD) for nanofluids, Int. J. Heat Mass Transfer 55 (2012) 4104- 4115."

[8] R. R. C.L. Tien, "Analyses of the effects of vapor pressure drop on heat pipe performance, Int. J. Heat Mass Transfer 17 (1974) 61-67."

[9] F. M.-M. Chen, "An analysis of the vapor flow and the heat conduction through the liquid-wick and pipe wall in a heat pipe with single or multiple heat sources, Int. J. Heat Mass Transfer 33 (9) (1990) 194-195."

[10] F. I. E.D. Huckaby, "I. Catton, Numerical simulation of heat pipe vapor dynamics using a collocation method, AIAA (1994) 0451."
[11] W. J. Legierski, "G.D. Mey, Measurements and simulations of transient characteristics of heat pipes, Microelectr. Reliab. 46 (2006) 109-115."

[12] F. B. Xiao, "A three-dimensional thermal-fluid analysis of flat heat pipes, Int. J. Heat Mass Transfer 51 (2008) 3113-3126."

[13] V. B. M. Shafahi, "K. Vafai, O. Manca, An investigation of the thermal performance of cylindrical heat pipes using nanofluids, Int. J Heat Mass Transfer 53 (2010) 376-383."

[14] S. P. J. K.H. Do, H.J. Ha, "Thermal resistance of screen mesh wick heat pipes using the water-based $\mathrm{A} 12 \mathrm{O} 3$ nanofluids, Int. J. Heat Mass Transfer 53 (2010) 5888-5894."

[15] H. . Vreedenburg, "Heat transfer between a fluidized bed and a horizontal tube,' Chemical Eng. Science, Vol. 9, pp. 52-66, 1958."

[16] Ainshtein, "I.G., 'Hydrodynamics and heat transfer in fluidized beds,' pp. 270- 272, Edited by Zabrodsky, S. S., M.I.T. press, Cambridge, 1966."

[17] M. Salwe, "Local heat transfer coefficient around a horizontal heating element in gas-solid fluidized bed," vol. 2, no. 6, pp. 344-348, 2013.

[18] S. Lechner, M. Merzsch, and H. J. Krautz, "Heat-transfer from horizontal tube bundles into fluidized beds with Geldart A lignite particles," Powder Technol., vol. 253, pp. 14-21, 2014.

[19] Hafidh Hassan Mohammed Al-Ghazali, "INVESTIGATION OF HEAT TRANSFER IN GAS-SOLID CIRCULATING FLUIDIZED BED .phD full thesis.” 2011.

[20] Q. F. Hou, Z. Y. Zhou, and A. B. Yu, "Gas-solid flow and heat transfer in fluidized beds with tubes: Effects of material properties and tube array settings," Powder Technol., vol. 296, pp. 59-71, 2016. 